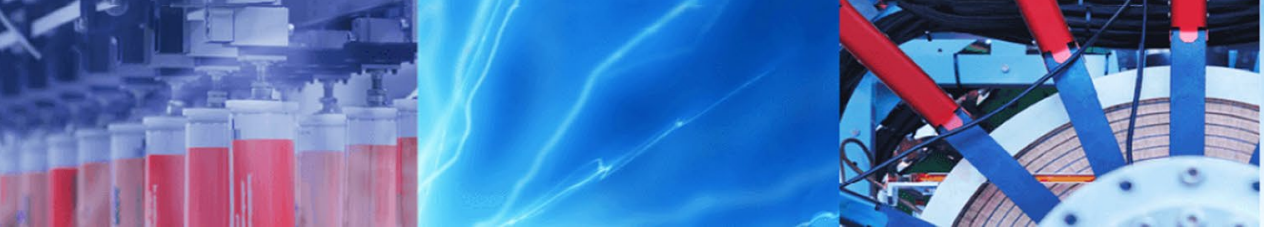

Research Article

\title{
Artificial lighting strategies in photobioreactors for bioenergy production by Scenedesmus obliquus CPCC05
}

\author{
Mariana Manzoni Maroneze ${ }^{1}$. Mariany Costa Deprá ${ }^{1} \cdot$ Leila Queiroz Zepka $^{1}$. Eduardo Jacob-Lopes ${ }^{1}$
}

Received: 15 March 2019 / Accepted: 22 November 2019 / Published online: 27 November 2019

(c) Springer Nature Switzerland AG 2019

\begin{abstract}
This work aimed to evaluate the artificial lighting strategies to increase the viability of microalgae biodiesel production. Different long-term, frequency, and short photoperiods were examined. Besides, the productivities of the process, the chemical composition of the biomass, biodiesel quality, and energy balance were assessed. The results showed that Scenedesmus obliquus CPCC05 can store sufficient energy to sustain cell growth for continuous periods of up to $2 \mathrm{~h}$ in the dark, without affecting the productivities of the process. The values for the maximum biomass $(63.88 \mathrm{mg} / \mathrm{L} \mathrm{h})$ and lipid $(18.9 \mathrm{mg} / \mathrm{L} \mathrm{h})$ productivities as well for the calorific value $(20.4 \mathrm{~kJ} / \mathrm{g})$ were obtained at a photoperiod of $24 \mathrm{t} / \mathrm{d}$. It was qualitatively observed that the photoperiod significantly influenced the fatty acid profile of single-cell oil and, consequently, the quality of the produced biodiesel. Finally, the use of photoperiods also proved to be an effective strategy to improve the energy balance and reduce the environmental impact of the microalgae biodiesel production process.
\end{abstract}

Keywords Light/dark cycle · Microalgae · Photoperiods · Lipid · Biodiesel

\section{Introduction}

It is commonly agreed that environmental deterioration and fossil fuel depletion are becoming two worldwide issues that threaten human development [1]. As a result, alternative sustainable and renewable sources of energy have been developed, such as the biofuels of the first, second, third, and fourth generation. Methyl esters of fatty acids, known as biodiesel, are non-toxic, biodegradable, and an excellent alternative to fossil diesel, since the combustion properties of this biofuel are similar to those of petroleum-based diesel [2].

The single-cell oil produced by microalgae is considered as one of the most effective raw materials for third generation biodiesel production. The advantages of biodiesel production from microalgae include the fast growth of cultures, high oil productivity, and low arable land demand [3]. Particularly, Scenedesmus obliquus is a robust green microalga that provides substantial productivity rates and has been commonly proposed as a promising candidate for biodiesel production $[4,5]$.

Given these aspects, to competitively produce this biofuel, it is crucial to reduce the raw material costs of production. The primary raw materials for the photosynthetic microalgae cultivation are nutrients, carbon dioxide, and light energy. The light energy can be provided by the sunlight, which is the most cost-effective energy source for microalgal production. However, it also has certain disadvantages, including day/night cycles, the influence of weather conditions, and seasonal changes. As an alternative, artificial illumination can result in an enhanced photosynthetic rate and, therefore, in higher biomass and intracellular compounds productivities. The continuous use of artificial light, however, results in increases in the electricity costs that will subsequently boost the final product costs $[6,7]$.

Eduardo Jacob-Lopes, ejacoblopes@gmail.com | 'Department of Food Science and Technology, Federal University of Santa Maria (UFSM), Santa Maria, RS 97105-900, Brazil. 
Conversely, the modulation of the light cycle appears as an alternative to reduce the demand for electrical energy in microalgal cultivations and then develop cheaper and more efficient processes. Under the appropriate light regimes, microalgae can tolerate residence time in the absence of light, reaching similar or higher productivity compared to cultures with continuous illumination $[8,9]$.

Furthermore, the light regime in which microalgal cultures are submitted is considered a determining factor in the cell productivity and chemical composition of biomass [10]. Several authors have previously reported that, besides reducing the operational costs of the process, the use of photoperiod can improve the photosynthetic rate as well as the productivity and quality of intracellular products [11-13].

In this regard, this work aimed to identify artificial lighting strategies that balance kinetic performance, energy cost and environmental impact for microalgal biodiesel production in photobioreactors. The study focused on assessing the influence of different photoperiods (longterm, frequency, and short photoperiods) on (i) productivities of the process, (ii) chemical composition of the biomass, (iii) biodiesel quality, (iv) energy balance, and on (v) life cycle assessment.

\section{Materials and methods}

\subsection{Microorganisms and culture media}

Axenic cultures of Scenedesmus obliquus CPCC05 were obtained from the Canadian Phycological Culture Centre. Stock cultures were propagated and maintained in a synthetic BG11 medium (Braun-Grunow medium) [14]. The incubation conditions used were $30^{\circ} \mathrm{C}$, the photon flux density of $30 \mu \mathrm{mol} \mathrm{m} \mathrm{m}^{-2} \mathrm{~s}^{-1}$ and a photoperiod of $12 \mathrm{~h}$.

\subsection{Photobioreactor design}

Measurements were carried out in a bubble column photobioreactor (Tecnal, Piracicaba-SP, Brazil). The system was built in $4 \mathrm{~mm}$ thick glass, an internal diameter of $7.5 \mathrm{~cm}$, a height of $75 \mathrm{~cm}$, and a nominal working volume of $2.0 \mathrm{~L}$. The dispersion system for the reactor consisted of a $1.5 \mathrm{~cm}$ diameter air diffuser located in the center of the column. The reactor was illuminated with $45 \mathrm{cool}$ white LED lamps of $0.23 \mathrm{~W}$ each and, situated on a photoperiod chamber situated on a photoperiod chamber with a timer digital of $600 \mathrm{~W}$ and stand by consumption of $1.6 \mathrm{~W}$. The $\mathrm{CO}_{2}$ /air mixture was adjusted to achieve the desired concentration of carbon dioxide in the airstream through three rotameters that measured the flow rates of carbon dioxide, air, and the mixture of gases, respectively.

\subsection{Obtaining the kinetic data in an experimental photobioreactor}

The experiments were conducted in bioreactors operating in continuous mode, which after the residence time of batch culture (Table 1), a feed synthetic BG11 medium was added to the bioreactor at dilution rates showed at Table 1. These data were obtained through preliminary batch mode experiments. At the same time, equal volumes of cell suspension were withdrawn from the bioreactor. The steady-state was considered to have been established after at least 3 volume charges, with a variation of cell dry weight less than $5 \%$.

The experimental conditions were the following: initial cell concentration of $100 \mathrm{mg} / \mathrm{L}$, isothermal reactor operating at a temperature of $26^{\circ} \mathrm{C}$, photon flux density of $150 \mu \mathrm{mol} \mathrm{m} \mathrm{m}^{-2} \mathrm{~s}^{-1}$, and continuous aeration of $1 \mathrm{VVM}$ (volume of air per volume of culture per minute) with the injection of air enriched with $15 \%$ carbon dioxide.

In the long-term photoperiods experiments, the light cycles evaluated were $(h: h)$ 24:0, 22:2, 20:4, 18:6, and 12:12 (light: dark). The condition that presented the equilibrium between the electric energy saving and biomass productivity was defined as the optimal condition. Thus, in the light/dark cycle frequency experiments, the cells were exposed to $22 \mathrm{~h}$ of light and $2 \mathrm{~h}$ of dark, where these $2 \mathrm{~h}$ were divided into six frequencies: $2,4,8,12,24$ and 48 times per day ( $t / d)$. To study the effects of short light/dark

Table 1 Dilution rates (D) and residence time of batch culture (RTBC) of different light conditions

\begin{tabular}{lll}
\hline Light regime & $\mathrm{D}\left(\mathrm{h}^{-1}\right)$ & $\mathrm{RTBC}(\mathrm{h})$ \\
\hline Long-term photoperiods & & \\
24:00 & 0.033 & 72 \\
22:02 & 0.033 & 48 \\
20:04 & 0.024 & 72 \\
18:06 & 0.012 & 72 \\
12:12 & 0.005 & 72 \\
Frequency photoperiods & & \\
2 t/d & 0.017 & 72 \\
4 t/d & 0.027 & 48 \\
8 t/d & 0.023 & 48 \\
12 t/d & 0.034 & 48 \\
24 t/d & 0.039 & 48 \\
48 t/d & 0.041 & 48 \\
Short photoperiods & & \\
0.91:0.09 & 0.035 & 48 \\
0.83:0.17 & 0.025 & 48 \\
0.75:0.25 & 0.022 & 48 \\
0.50:0.50 & 0.022 & 72 \\
\hline
\end{tabular}


cycles, four different cycles of (s: s) 0.91:0.09, 0.83:0.17, 0.75:0.25, and 0.50:0.50 (light: dark) were set every one second.

The cell concentration was monitored every $24 \mathrm{~h}$ during the growth phase of the microorganism. The tests were carried out in duplicate, and the kinetic data referred to the mean of four repetitions.

\subsection{Kinetic parameters}

Biomass data were used to calculate the biomass productivity $[\mathrm{PX}=\mathrm{Xmax} \cdot \mu \max , \mathrm{mg} / \mathrm{L} \mathrm{h}]$ and lipid productivity $[P L=P X \cdot L C, m g / L ~ h]$, where $X \max$ is the maximum biomass concentration $(\mathrm{mg} / \mathrm{L}), \mu$ max is the maximum specific growth rate $\left(\mathrm{h}^{-1}\right)$ and $\mathrm{LC}$ is lipid content of the biomass (\%).

\subsection{Analytical methods}

Cell concentration was evaluated gravimetrically by filtering a known volume of culture medium through a $0.45 \mu \mathrm{m}$ filter (Millex FG, Billerica-MA, USA) and drying at $60^{\circ} \mathrm{C}$. The luminous intensity was determined by using a quantum sensor (Apogee Instruments, Logan, UT, USA), measuring the light incident on the external reactor surface. Thermostats controlled the temperature. The flow rates of carbon dioxide, air, and $\mathrm{CO}_{2}$ enriched air were determined using rotameters (AFSG 100 Key Instruments, Trevose, PA, USA).

The chemical composition of microalgal biomass was performed based on the method described in AOAC [15], except to total lipid concentration of the biomass, which was determined gravimetrically by the modified Bligh and Dyer method [16]. The biomass calorific value was calculated by the Atwater System, using factors of $17 \mathrm{~kJ} / \mathrm{g}$ for protein, $37 \mathrm{~kJ} / \mathrm{g}$ for lipid and $17 \mathrm{~kJ} / \mathrm{g}$ for total carbohydrate content [17].

The method of Hartman and Lago [18] was used to saponify and esterify the dried lipid extract to obtain the fatty acid methyl esters. Fatty acid composition was determined by using a VARIAN $3400 C X$ gas chromatograph (Varian, Palo Alto, CA, USA. The fatty acid methyl esters were identified by comparison of the retention times with the authentic standards from FAME Mix-37 (P/N 47885-U, Sigma-Aldrich, St. Louis, MO USA) and quantified through area normalization by software T2100p Chromatography Station (Plus Edition) v9.04.

The fuel properties of biodiesel (ester content, EC; cetane number, $\mathrm{CN}$; iodine value, II; degree of unsaturation, DU; saponification value, $\mathrm{SV}$; long-chain saturated factor, LCSF; cold filter plugging point, CFPP; cloud point, CP; allylic position equivalents, $\mathrm{APE}$; bis-allylic position equivalents, BAPE; oxidation stability, OS; higher heating value, $H V V$; kinematic viscosity, $\mu$ and kinematic density, $\rho$ ) were determined through the software BiodieselAnalyzer@ 1.1, which estimates biodiesel properties based on the fatty acid profile of the parent oil, through a system of empirical equations [19].

\subsection{Energy balance}

The net energy ratio (NER) $\left[\right.$ NER $=\sum$ Eout $/ \sum$ Ein $]$ of a system was defined as the ratio of the total energy produced per day (energy content of the residual biomass, $\mathrm{MJ} / \mathrm{d}$ ) over the energy required for lighting and timer digital of the photobioreactor per day $(\mathrm{MJ} / \mathrm{d})$, where Eout is the renewable energy output and Ein is the fossil fuel energy input.

To calculate the net energy balance (NEB) [NEB $=\sum$ inputs $-\sum$ outputs] the inputs were considered as the energy required for lighting the photobioreactor per day and the outputs as the energy produced per day.

\subsection{Life cycle assessment}

The life cycle assessment tool was used to evaluate the potential environmental impacts according to categories of energy resource (ER), global warming potential (GWP), acidification potential (AP), eutrophication potential (EP), photochemical ozone creation potential (SMOG), ozone depletion potential (ODP), and ecotoxicity (ECO) [20]. The objective and scope of the application of this LCA were to evaluate the environmental footprint of the energy requirements for long term photoperiods. Besides, the functional unit considered was the energy demand for 1 operation day in the microalgal photobioreactors under the modeling of long-term, frequency and short photoperiods.

In the life cycle impact assessment phase, the characterization stage the results of the indicators for each impact category was quantified through mathematical modelling

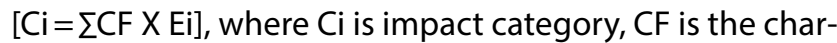
acterization factor, and Ei is emission inventory, expressed in mass released into the environment per functional unit. In addition, Table 2 presents the respective impact category indicators using characterization factors.

\subsection{Statistical analysis}

Analysis of variance (one-way ANOVA) and Tukey's test $(p<0.05)$ were used to test the differences between the photoperiods. To elucidate the relationship between the production parameters of lipids and between the fatty acid and biodiesel properties under different lighting condition, multivariate analysis via principal component analysis (PCA) was performed. The analyses were performed with the software Statistica 7.0 (StatSoft, Tulsa, OK, USA). 
Table 2 Factors of characterization of environmental impacts of 1 $\mathrm{kWh}$ in processes

\begin{tabular}{lll}
\hline Categories & Unit & Impact \\
\hline Ozone depletion & $\mathrm{kg} \mathrm{CFC}-11$ eq & $9.39 \times 10^{-8}$ \\
Global warming & $\mathrm{kg} \mathrm{CO}_{2}$ eq & $3.08 \times 10^{-1}$ \\
Smog & $\mathrm{kg} \mathrm{O}_{3}$ eq & $6.84 \times 10^{-3}$ \\
Acidification & $\mathrm{kg} \mathrm{SO}_{2}$ eq & $1.64 \times 10^{-3}$ \\
Eutrophication & $\mathrm{kg} \mathrm{N} \mathrm{eq}^{-4}$ & $5.86 \times 10^{-4}$ \\
Ecotoxicity & $\mathrm{CTUe}$ & 2.18 \\
Fossil fuel depletion (coal) & $\mathrm{MJ}$ & $6.65 \times 10^{-1}$ \\
\hline
\end{tabular}

\section{Results and discussion}

The growth of microalgal culture depends on various abiotic factors, such as temperature, level of nutrients, and available light. Among these factors, the light influences directly the photosynthesis mechanism being an essential factor in reaching optimal growth conditions for the culture [11]. In this sense, Fig. 1 shows the effect of long-term photoperiods (a), frequency photoperiods (b) and short photoperiods (c) on biomass and lipid productivity.

As shown in Fig. 1a, the biomass productivity is reduced as the dark period's increase. This is associated with the photolimitation condition that occurs when there is insufficient light to maintain metabolism [21]. The maximum cell productivity $(47.02 \mathrm{mg} / \mathrm{L})$ was found in the photoperiod of 24:00 h (light: dark), followed by 22:02 h, which has biomass productivity of $42.66 \mathrm{mg} / \mathrm{L} \mathrm{h}$. Nevertheless, in these two conditions, no significant difference (Tukey's test $p<0.05$ ) was observed. These results show that Scenedesmus obliquus CPCC05 can store sufficient energy to sustain cell metabolism for periods of up to $2 \mathrm{~h}$ uninterrupted in the dark, without affecting the biomass productivity. Comparatively, Krzemińska et al. [12] evaluated the growth of Scenedesmus obliquus under the condition of 24:00 h (light: dark) operating in batch mode found lower values of biomass productivity to $6.25 \mathrm{mg} / \mathrm{L} \mathrm{h}$. Likewise, Vendruscolo et al. [22] showed values of the $16.3 \mathrm{mg} / \mathrm{L} \mathrm{h}$. Besides, similar results were evidenced in cyanobacterium Aphanothece microscopica Nägeli by Jacob-Lopes [8]. This species, under different photoperiods, proved to be able to maintain its biomass productivity, growth rate and carbon dioxide fixation rate for up to $2 \mathrm{~h}$ in the dark.

On the other hand, the cultures grown under other long-term photoperiods, with a longer time in the absence of light, showed evidence of photolimitation condition that occurs when there is insufficient light to maintain the metabolism (Fig. 1a) [23, 24]. Jacob-Lopes and coworkers [8] also associate the low cell growth under conditions with long-term in the dark to the limited carbon source for cell growth. This because the
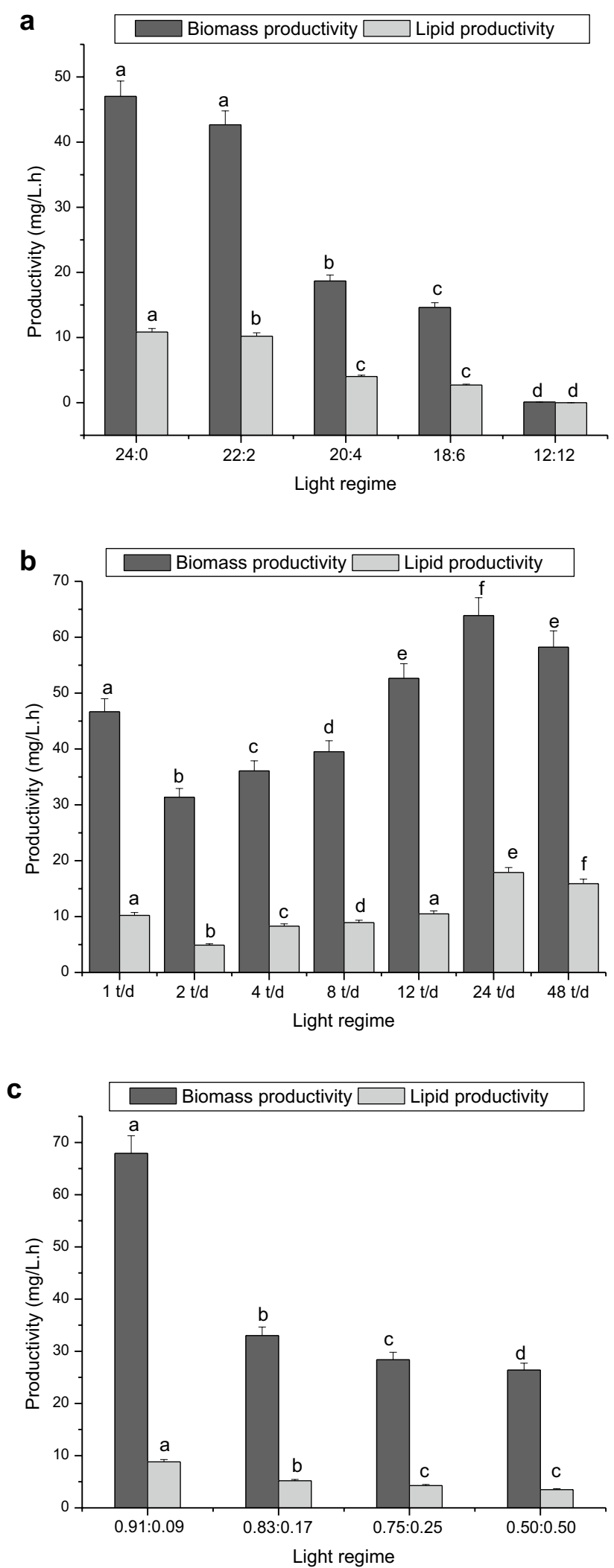

Fig. 1 Effects of long-term photoperiods (a), frequency photoperiods (b) and short photoperiods (c) on the biomass and lipid productivity. Same letters indicate that data did not differ statistically (Tukey test, $p \leq 0.05$ ) 
microalgae are unable to use inorganic carbon sources in the absence of light, and the organic carbon concentrations in the culture medium were insufficient for the energy maintenance of respiratory metabolism. However, for the different long-term photoperiods, the light regime significantly influenced the production of microalgal biomass.

The results showed in Fig. 1a indicated that the photoperiod of 22:2 $\mathrm{h}$ was the condition that presented the equilibrium between the electric energy saving and biomass productivity. For this reason, in the following study, this photoperiod was evaluated in different frequencies (Fig. 1b), as a strategy to improve the performance of the process. An improvement can be seen in the productivity of the process, as it increases the number of frequencies per day. This behavior was observed up to $24 \mathrm{t} / \mathrm{d}$, where this condition showed the best cell productivity value ( $63.88 \mathrm{mg} / \mathrm{L} \mathrm{h}$ ), followed by $48 \mathrm{t} / \mathrm{d}(58.22 \mathrm{mg} / \mathrm{L} \mathrm{h})$.

It was also observed that the photoperiod of 24 times per day had biomass productivity $35.8 \%$ higher than experiments with constant illumination. This can be associated with the photoinhibition phenomenon, where, when the cells are exposed to continuous illumination, there may be an excess of light energy. This effect is caused by a photo-oxidation reaction inside the cell due to excess light that cannot be absorbed by the photosynthetic apparatus [23].

The short light/dark cycles are very fast alternations between high light intensities and darkness, also called a flashing light effect. This light condition has been experimentally proven to be one of the most promising light regimes in microalgal cultivation [7]. For this reason, the effects of short light/dark cycle on biomass productivity are shown in Fig. 1c. The best results are evidenced at 0.91:0.09 s (light: dark), with biomass productivity of $67.9 \mathrm{mg} / \mathrm{L}$ h. Moreover, the photoperiods of 0.91:0.09, 0.83.0.17, and 0.75:0.25 s (light: dark) presented results of biomass productivity superior to the culture with constant illumination. The improvement of cellular growth under short photoperiods could be as a result of an enhanced dark respiration rates following a period of photosynthesis in light. This mechanism is known as enhanced postillumination respiration $[7,23]$.

Changes in light quantity not only affect photosynthesis and the growth rate of the microorganism but also influence the activity of cellular metabolism and chemical composition of the biomass. Lipids are intracellular products of microalgae, and for this reason, lipid productivity is the product of lipid content and biomass productivity. Thus, the best lipid producer has to combine biomass productivity and lipid content [2]. In this sense, Fig. 1 shows the lipid productivity, and Fig. 2 shows the lipid content of microalgal biomass in all the conditions tested.

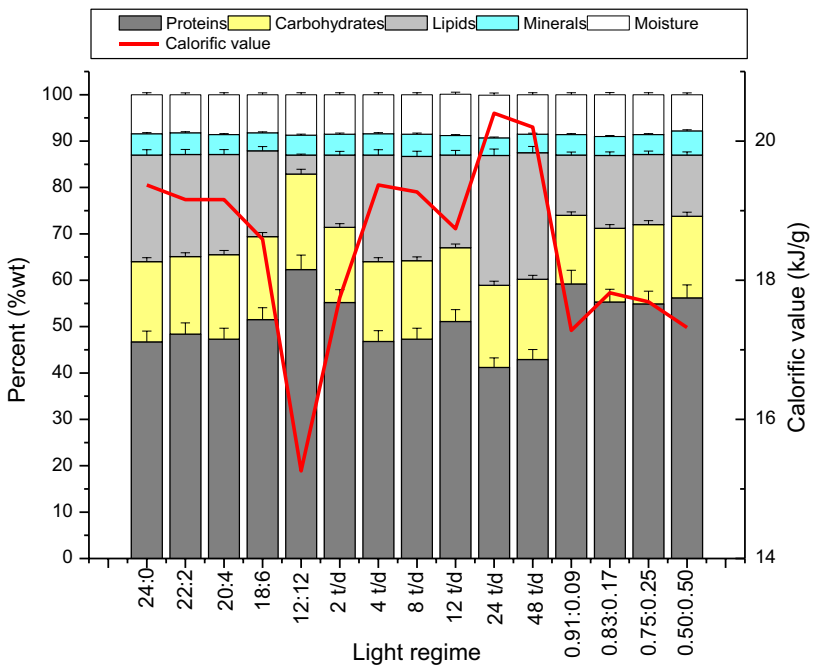

Fig. 2 Biochemical composition and energy value of the microalgal biomass in different photoperiods

The best results for lipid production are evidenced at a frequency photoperiod of $24 \mathrm{t} / \mathrm{d}$, which presents a lipid content of $28.02 \%$, and lipid productivity of $18.89 \mathrm{mg} / \mathrm{L} \mathrm{h}$. On the other hand, the worst light condition for lipid production was at a long-term photoperiod of 12:12 $\mathrm{h}$, whereas that, besides the low cell growth, also has low lipid content, resulting in lipid productivity of $0.004 \mathrm{~g} / \mathrm{L}$ h. Similarly, studies evaluating lipid productivity at a frequency photoperiod of $24 \mathrm{t} / \mathrm{d}$ showed values of $2.56 \mathrm{mg} / \mathrm{L} \mathrm{h}$ for cultivation in bioreactors operating on batch mode [25]. Besides, the same behavior for Scenedesmus obliquus was found at a long-term photoperiod of 12:12, corresponding to lower values in the order of $0.0023 \mathrm{~g} / \mathrm{L} h$ [21]. This may be due to lipid/glucan biosynthesis, and carbon fixation occurs during the light period. Moreover, the light will generally stimulate fatty acid synthesis to convert excess light to chemical energy in order to avoid photo-oxidative damage [26].

Figure 2 also shows the biochemical composition in terms of the content of total proteins and carbohydrates for all light conditions tested. In the protein fraction, a small variation between the light conditions was verified. The results showed that the increase of protein content corresponds with the decrease of lipid content. The highest value (62.3\%) was found in the photoperiod of $12: 12 \mathrm{~h}$, and the lower (41.2) was at a frequency photoperiod of 24 $\mathrm{t} / \mathrm{d}$. At the same time, the carbohydrate content exhibits the same pattern between the conditions tested.

The calorific value is another parameter that must be considered to determine the feasibility of biofuel feedstock production from microalgae [27]. Figure 2 also presents the calorific value for all the photoperiods evaluated. The improvement in calorific value is linked 
to the increase in lipid content rather than any change in other components such as protein and carbohydrates. As expected, the higher calorific value was found with a frequency photoperiod of $24 \mathrm{t} / \mathrm{d}(20.4 \mathrm{~kJ} / \mathrm{g})$ that also had the highest lipid content of $28 \%$, followed by $48 \mathrm{t} / \mathrm{d}$, which presents a calorific value of $20.2 \mathrm{~kJ} / \mathrm{g}$ and lipid content of $27.32 \%$. In other words, these photoperiods are more viable for biodiesel production in quantitative terms.

However, the qualitative profile of the lipid fraction should also be considered to choose an ideal growing condition for bioenergy production. Table 3 shows the fatty acid (FA) composition of the oil extracts from the sixteen light/dark cycle evaluated here. Eleven majority FAs were identified and, as expected, there was variability in FA composition for the different light conditions.

In the long-term photoperiods, the light: dark cycle of 24:0, 22:2, and 20:4 $\mathrm{h}$ showed a similar profile, which is predominantly polyunsaturated (42.34-50.9\%). In comparison, the photoperiod of 18:6 showed a predominantly saturated profile (53.37\%), followed by polyunsaturated FAs (28.13\%). On the other hand, the light cycle of $12: 12 \mathrm{~h}$ was the condition with the highest fraction of SFA $(80.5 \%)$, followed by MUFA (18.8\%). In terms of lipid content, this photoperiod showed the lowest value among the longterm photoperiods. This could be explained by the fact that lipids and fatty acids were oxidized when cells require energy in the dark during insufficient light for photosynthesis. As unsaturations are prone to oxidation, the polyunsaturated FAs are firstly degraded [28, 29].

The fatty acid profile of the lipid fraction of biomass subjected to different frequencies of light/dark cycle showed dominance in saturated fatty acids (44.73-51.60\%), followed by saturated ones (27.93-42.34\%). The dominant fatty acids were palmitic acid (C16:0), a-linolenic acid (C18:3n6) and linoleic acid (C18:2n6) for all the treatments. In this set of data, there were no pronounced differences in lighting conditions. Additionally, this major fatty acid profile corroborates most studies evaluating Scenedemus obliquus [30-33].

Finally, in terms of the fatty acid profile of short photoperiods, the lipid fraction of biomass indicated that this lipid profile was completely different from the other light conditions tested. Under these conditions, saturated fatty acids (51.6-85.7\%) were the majority for all short light/dark cycles, followed by monounsaturated ones (8.9-32.7\%).

To assess the potential of biodiesel as a complement or substitute traditional diesel fuel in engines, the properties of biodiesel, such as density, viscosity, flash point, cold filter plugging point, solidifying point, and heating value, were determined. A comparison of these properties of biodiesel from microalgal oils and US [34], European [35], and Brazilian [36] biodiesel standards is shown in Table 4.
Different light conditions have shown a significant effect on the fatty acid profile and, as a result, biodiesel properties were also affected. The Table 4 demonstrated that except for the parameters cetane number and viscosity, all the photoperiods tested comply with the limits established by the international standards.

$\mathrm{CN}$ is a prime indicator of fuel quality related to the ignition quality of a fuel in a diesel engine. The $\mathrm{CN}$ of a diesel fuel is determined by the ignition delay time. A higher $\mathrm{CN}$ value means better ignition properties and engine performance. The primary reference fuel on this scale is hexadecane or cetane, with a $\mathrm{CN}$ value of 100 and the minimum value on this scale is 15 . The international standards requires a minimum CN of 45 (ANP 255), 47 (ASTM D6751), or 51 (EN14214). According to Ramos et al. [36], the longer the fatty acid carbon chains and the more saturated the fatty acids, the higher the cetane number. This explanation was confirmed by the light regimes of $24: 0 \mathrm{~h}, 22: 2 \mathrm{~h}$, $20: 4 \mathrm{~h}, 1 \mathrm{t} / \mathrm{d}, 8 \mathrm{t} / \mathrm{d}, 12 \mathrm{t} / \mathrm{d}$, and $48 \mathrm{t} / \mathrm{d}$, which showed the highest PUFAs values and consequently lower $\mathrm{CN}$ values (below the values established by the highest international standards).

The kinematic viscosity of biodiesel is another significant fuel property. The main problems associated with this parameter are observed for high-viscosity oils. This highviscosity affects the atomization of a fuel on injection into the combustion chamber and, thereby, ultimately the formation of engine deposits. For this reason, high viscosity is the major fuel property why neat vegetable oils have been largely abandoned as alternative diesel fuel. Conversely, Table 4 showed that all conditions tested were lower than that of international standards established for kinematic viscosity. Thus, both the problem of low viscosity microalgae biodiesel and high viscosity of vegetable oils could be solved by blending. Blending has been extensively used and is considered a good and feasible method to improve the biodiesel quality [30, 37-39].

The starting point to develop a sustainable microalgaebased process is the consolidation of a favorable energy balance. For this reason, the NER and NEB are parameters of quantification, whose application is to demonstrate the difference between the amount of available energy and the amount of energy used to obtain in operations. Thus, for processes to be considered technically viable, it has been theoretically established that NER should be greater than 1 and negative NEB [40]. However, most of the industrial processes in operation do not attend these requirements, boosting their optimization to achieve these parameters. In this sense, Table 5 shows the energy balance of microalgae culture in different light regimes.

The results shown in Table 5 indicated that the energy required to supply the artificial lighting of the photobioreactor was lower than that produced in all light 


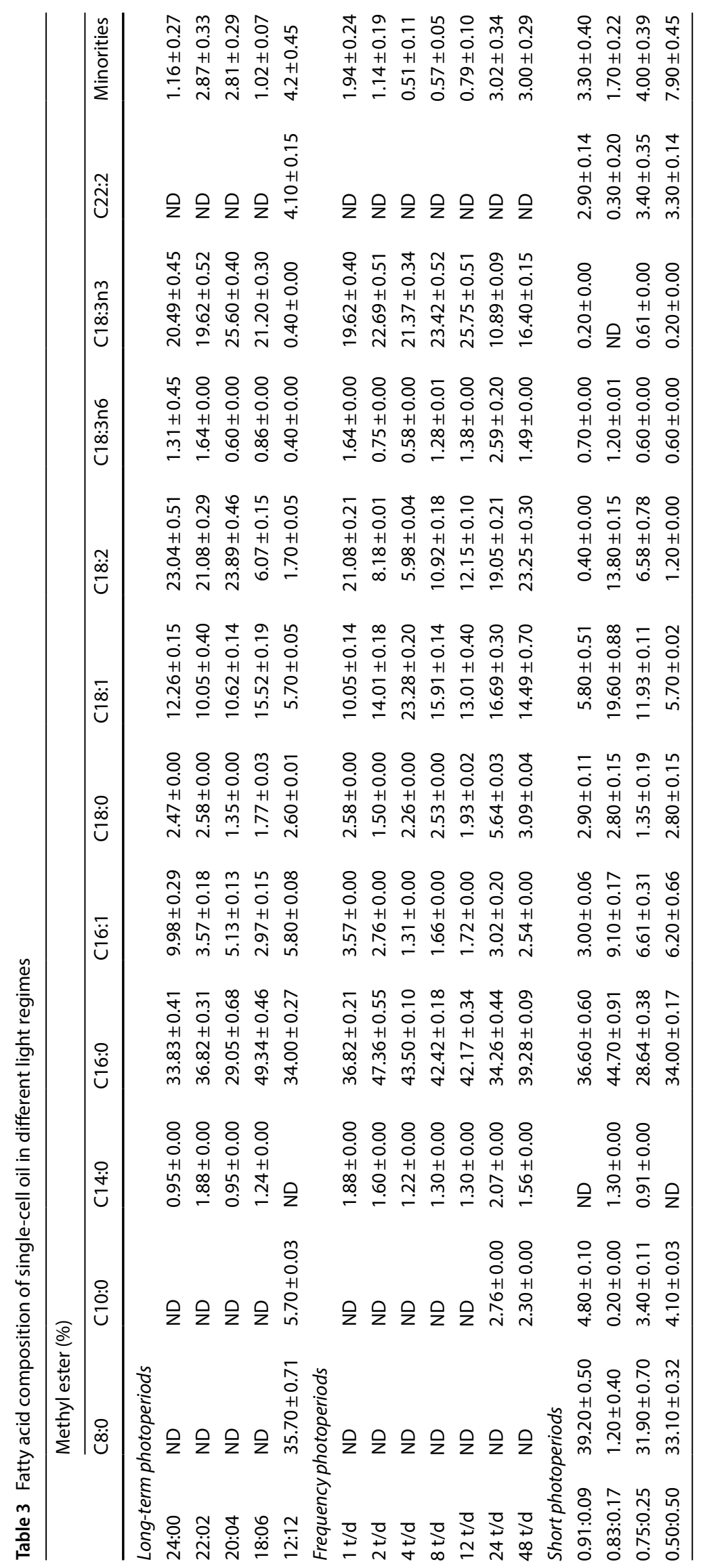




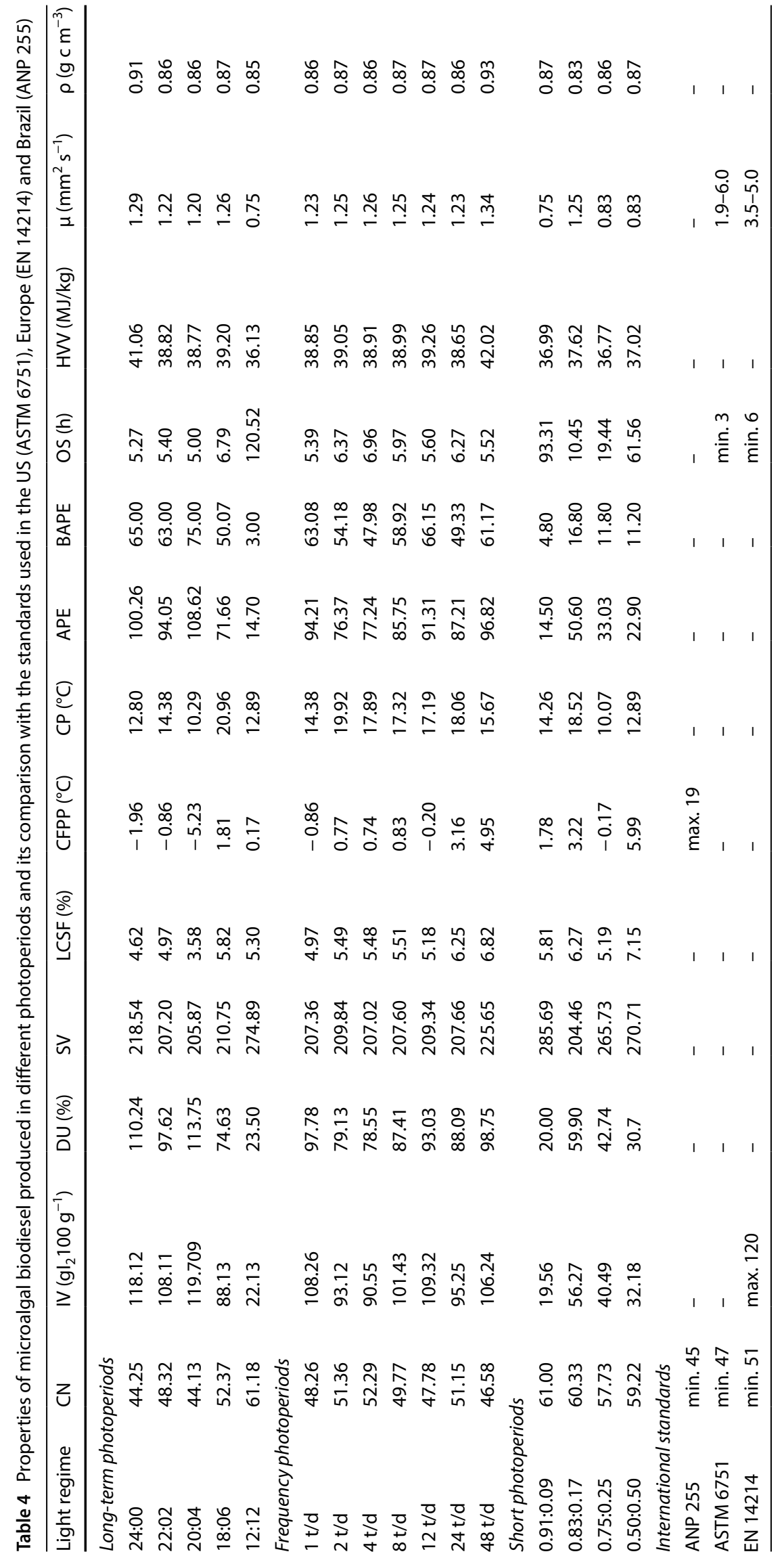


Table 5 Analysis of the net energy ratio (NER) and net energy balance (NEB) of the microalgal culture in different light regimes

\begin{tabular}{|c|c|c|c|c|c|}
\hline Light regime & $\begin{array}{l}\text { Energy require- } \\
\text { ments }(\mathrm{MJ} / \mathrm{d})\end{array}$ & $\begin{array}{l}\text { Cost energy require- } \\
\text { ments (USD/d) }\end{array}$ & $\begin{array}{l}\text { Energy produced } \\
(\mathrm{MJ} / \mathrm{d})\end{array}$ & NER & NEB \\
\hline \multicolumn{6}{|c|}{ Long-term photoperiods } \\
\hline $24: 00$ & 52.73 & 1.90 & 21.84 & 0.41 & 30.89 \\
\hline $22: 02$ & 48.34 & 1.74 & 21.44 & 0.44 & 26.9 \\
\hline 20:04 & 43.96 & 1.58 & 8.58 & 0.19 & 35.38 \\
\hline $18: 06$ & 39.57 & 1.42 & 6.50 & 0.16 & 33.07 \\
\hline $12: 12$ & 26.42 & 0.95 & 0.00015 & 0 & 26.41 \\
\hline \multicolumn{6}{|c|}{ Frequency photoperiods } \\
\hline $1 \mathrm{t} / \mathrm{d}$ & 48.34 & 1.74 & 21.44 & 0.44 & 26.9 \\
\hline $2 t / d$ & 48.34 & 1.74 & 13.34 & 0.27 & 35.0 \\
\hline $4 \mathrm{t} / \mathrm{d}$ & 48.34 & 1.74 & 16.65 & 0.34 & 31.69 \\
\hline $8 \mathrm{t} / \mathrm{d}$ & 48.34 & 1.74 & 18.26 & 0.37 & 30.08 \\
\hline $12 t / d$ & 48.34 & 1.74 & 23.61 & 0.48 & 24.73 \\
\hline $24 \mathrm{t} / \mathrm{d}$ & 48.34 & 1.74 & 31.21 & 0.64 & 17.13 \\
\hline $48 \mathrm{t} / \mathrm{d}$ & 48.34 & 1.74 & 28.07 & 0.58 & 20.27 \\
\hline \multicolumn{6}{|c|}{ Short photoperiods } \\
\hline 0.91:0.09 & 48.34 & 1.74 & 28.13 & 0.58 & 20.21 \\
\hline 0.83:0.17 & 43.96 & 1.58 & 14.25 & 0.32 & 29.71 \\
\hline $0.75: 0.25$ & 39.57 & 1.42 & 12.03 & 0.30 & 27.54 \\
\hline $0.50: 0.50$ & 26.42 & 0.95 & 10.91 & 0.41 & 15.51 \\
\hline
\end{tabular}

conditions, except for the photoperiod of 12:12 h (light: dark) that presented a positive NEB and a NER of 0 .

Moreover, although the values of NER and NEB did not reach the necessary values to be considered viable processes, the modulation of photoperiods demonstrated to be an effective strategy to reduce the energy requirements and increased energy produced. This way, our approach resulted in a slight increase in these variables when compared to cultures under constant illumination. Among all the conditions tested, the best values for NER (0.64) and NEB (17.13) were found at a frequency photoperiod of $24 \mathrm{t} / \mathrm{d}$, followed by $48 \mathrm{t} / \mathrm{d}$ with a NER and NEB of 0.58 and 20.27, respectively. Still, associated with energy demand, it can be observed that energy consumption was reduced from $1.90 \mathrm{USD} / \mathrm{d}$ under constant illumination to $1.74 \mathrm{UDS} / \mathrm{d}$ photoperiod of 22:02 h (light: dark), providing an enhanced in the energy ratio as well as a reduction of $8 \%$ of electricity costs.

Besides, when assessing the environmental impacts related to the different artificial illuminations strategies (considering a functional unit of 1 day of operation), in a system continuously illuminated (long-term photoperiod 24:0), we can estimate (Table 6) an ecotoxicity of $3.10 \times 10^{1}$ CTUe, energy resource of $9.73 \mathrm{MJ}$, global warming potential of $4.50 \mathrm{~kg} \mathrm{CO}_{2} \mathrm{eq}$, photochemical oxidation potential of $1.00 \times 10^{-1} \mathrm{~kg} \mathrm{O}_{3}$ eq, acidification potential of $2.40 \times 10^{-2} \mathrm{~kg} \mathrm{SO}_{2}$ eq, eutrophication potential of $8.57 \times 10^{-3} \mathrm{~kg} \mathrm{~N}$ eq and ozone depletion potential of $1.37 \times 10^{-6} \mathrm{~kg} \mathrm{CFC}-11 \mathrm{eq}$.
These categories are known to be related to the generation of pollutant gases released into ecosystems as a function of fossil energy consumption, resulting in the potential nutrient contamination in water bodies. Also, the release of volatile compounds contributes considerably to ozone layer degradation. Consequently, these pollutants create substantial risks to public health, especially where there is no control over emissions. Thus, regardless of the photoperiod strategy adopted, the decision-making to replace the energy matrix with clean sources can bring immediate results to reduce environmental impacts [41].

Obviously, there is a direct reduction of the environmental impact with the illumination time. In this sense, a trade-off should be achieved, considering besides the environmental impacts, the energy costs, and the process performance. In this sense, through data analysis (Tables 3, 5, 6, and Figs. 1 and 2), the frequency photoperiod of 24 $\mathrm{t} / \mathrm{d}$ seems to be the artificial illumination condition that balances all these variables.

Finally, in order to organize the observed data and facilitate the interpretation, a principal component analysis (PCA) was used. PCA is a powerful statistical tool to analyze the interrelationships among a large number of variables and to explain these variables in a reduced number of information (principal components).

The first PCA was performed to examine the relationship between the feedstock production parameters. Figure $1 \mathrm{a}$ and $\mathrm{b}$ shows the weights (variables) and scores (treatments), respectively, from the two major principal 
Table 6 Environmental impacts assessments for longterm, frequency photoperiods, and short photoperiods

\begin{tabular}{llllllll}
\hline Impact category & ODP & GWP & SMOG & AP & EP & ECO & ER \\
\hline Long-term photoperiods & & & & & & \\
$24: 0$ & $1.37 \times 10^{-6}$ & 4.50 & $1.00 \times 10^{-1}$ & $2.40 \times 10^{-2}$ & $8.57 \times 10^{-3}$ & $3.10 \times 10^{1}$ & 9.73 \\
$22: 2$ & $1.26 \times 10^{-6}$ & 4.13 & $9.17 \times 10^{-2}$ & $2.20 \times 10^{-2}$ & $7.86 \times 10^{-3}$ & $2.92 \times 10^{1}$ & 8.92 \\
$20: 4$ & $1.18 \times 10^{-6}$ & 3.76 & $8.35 \times 10^{-2}$ & $2.00 \times 10^{-2}$ & $7.15 \times 10^{-3}$ & $2.66 \times 10^{1}$ & 8.11 \\
$18: 06$ & $1.03 \times 10^{-6}$ & 3.38 & $7.51 \times 10^{-2}$ & $1.80 \times 10^{-2}$ & $6.4 \times 10^{-3}$ & $2.39 \times 10^{1}$ & 7.30 \\
$12: 12$ & $6.88 \times 10^{-7}$ & 2.25 & $5.01 \times 10^{-2}$ & $1.20 \times 10^{-2}$ & $4.29 \times 10^{-3}$ & $1.59 \times 10^{1}$ & 4.87 \\
Frequency photoperiod & & & & & & \\
1 t/d & $1.26 \times 10^{-6}$ & 4.13 & $9.17 \times 10^{-2}$ & $2.20 \times 10^{-2}$ & $7.86 \times 10^{-3}$ & $2.92 \times 10^{1}$ & 8.92 \\
2 t/d & $1.26 \times 10^{-6}$ & 4.13 & $9.17 \times 10^{-2}$ & $2.20 \times 10^{-2}$ & $7.86 \times 10^{-3}$ & $2.92 \times 10^{1}$ & 8.92 \\
$4 \mathrm{t} / \mathrm{d}$ & $1.26 \times 10^{-6}$ & 4.13 & $9.17 \times 10^{-2}$ & $2.20 \times 10^{-2}$ & $7.86 \times 10^{-3}$ & $2.92 \times 10^{1}$ & 8.92 \\
$8 \mathrm{t} / \mathrm{d}$ & $1.26 \times 10^{-6}$ & 4.13 & $9.17 \times 10^{-2}$ & $2.20 \times 10^{-2}$ & $7.86 \times 10^{-3}$ & $2.92 \times 10^{1}$ & 8.92 \\
$12 \mathrm{t} / \mathrm{d}$ & $1.26 \times 10^{-6}$ & 4.13 & $9.17 \times 10^{-2}$ & $2.20 \times 10^{-2}$ & $7.86 \times 10^{-3}$ & $2.92 \times 10^{1}$ & 8.92 \\
24 t/d & $1.26 \times 10^{-6}$ & 4.13 & $9.17 \times 10^{-2}$ & $2.20 \times 10^{-2}$ & $7.86 \times 10^{-3}$ & $2.92 \times 10^{1}$ & 8.92 \\
$48 \mathrm{t} / \mathrm{d}$ & $1.26 \times 10^{-6}$ & 4.13 & $9.17 \times 10^{-2}$ & $2.20 \times 10^{-2}$ & $7.86 \times 10^{-3}$ & $2.92 \times 10^{1}$ & 8.92 \\
Short photoperiod & & & & & & & \\
$0.91: 0.91$ & $1.26 \times 10^{-6}$ & 4.13 & $9.17 \times 10^{-2}$ & $2.20 \times 10^{-2}$ & $7.86 \times 10^{-3}$ & $2.92 \times 10^{1}$ & 8.92 \\
$0.83: 0.17$ & $1.18 \times 10^{-6}$ & 3.76 & $8.35 \times 10^{-2}$ & $2.00 \times 10^{-2}$ & $7.15 \times 10^{-3}$ & $2.66 \times 10^{1}$ & 8.11 \\
$0.75: 0.25$ & $1.03 \times 10^{-6}$ & 3.38 & $7.51 \times 10^{-2}$ & $1.80 \times 10^{-2}$ & $6.4 \times 10^{-3}$ & $2.39 \times 10^{1}$ & 7.30 \\
$0.50: 0.50$ & $6.88 \times 10^{-7}$ & 2.25 & $5.01 \times 10^{-2}$ & $1.20 \times 10^{-2}$ & $4.29 \times 10^{-3}$ & $1.59 \times 10^{1}$ & 4.87 \\
\hline
\end{tabular}

components. Together, the principal component 1 (PC1) and principal component 2 (PC2) explained $93.14 \%$ of the overall variance. Not surprisingly, the lipid content was highly correlated with the calorific value. It was evident that both protein and carbohydrates did not influence any of the oil production parameters. As discussed herein above, the lipids are intracellular products and, therefore, the lipid productivity depends on both the lipid content as biomass productivity. This relationship is clearly shown in Fig. 3a. As the parameters NER and NEB are mainly based on biomass productivity, they were clustered together on the top left-hand of the plot. The Fig. 3b shows that the light regimes clustered at the left lower quadrant are the conditions with the best results in terms of single-cell oil production.

PCA was also carried out to find out the relationship between the fatty acid profile and biodiesel properties of different culture treatments (Fig. 4a and b). As shown in Fig. $4 a, b, P C A 1$ and PCA2 explained $72.19 \%$ of the observed variation. It was clearly shown that the SFA content is closely related to $\mathrm{CN}$ and $\mathrm{OS}$ of the biodiesel, while the PUFA content is related to IV of the biodiesel. The Fig. 4b explained that the short photoperiods and 12:12 h (light: dark) are linked to higher CN, OS and SFA content, whereas the other long-term photoperiods were associated with higher PUFA content. In the frequencies' photoperiods there was a balance between PUFA and MUFA. The short photoperiods are more related with the saturated fatty acids e, consequently with higher values of $\mathrm{CN}$ and $\mathrm{OS}$.

\section{Conclusion}

The productivities of the process, chemical composition, calorific value of biomass, and properties of biodiesel were significantly influenced by the photoperiod. The condition that presented better both quantitative and qualitative values for biodiesel production was the frequency photoperiod of 24 times per day. The modulation of photoperiods demonstrated to be an enhanced strategy to improve the energy balance of the process, allowing the use of artificial lighting as a worthwhile alternative for microalgal biodiesel production. 

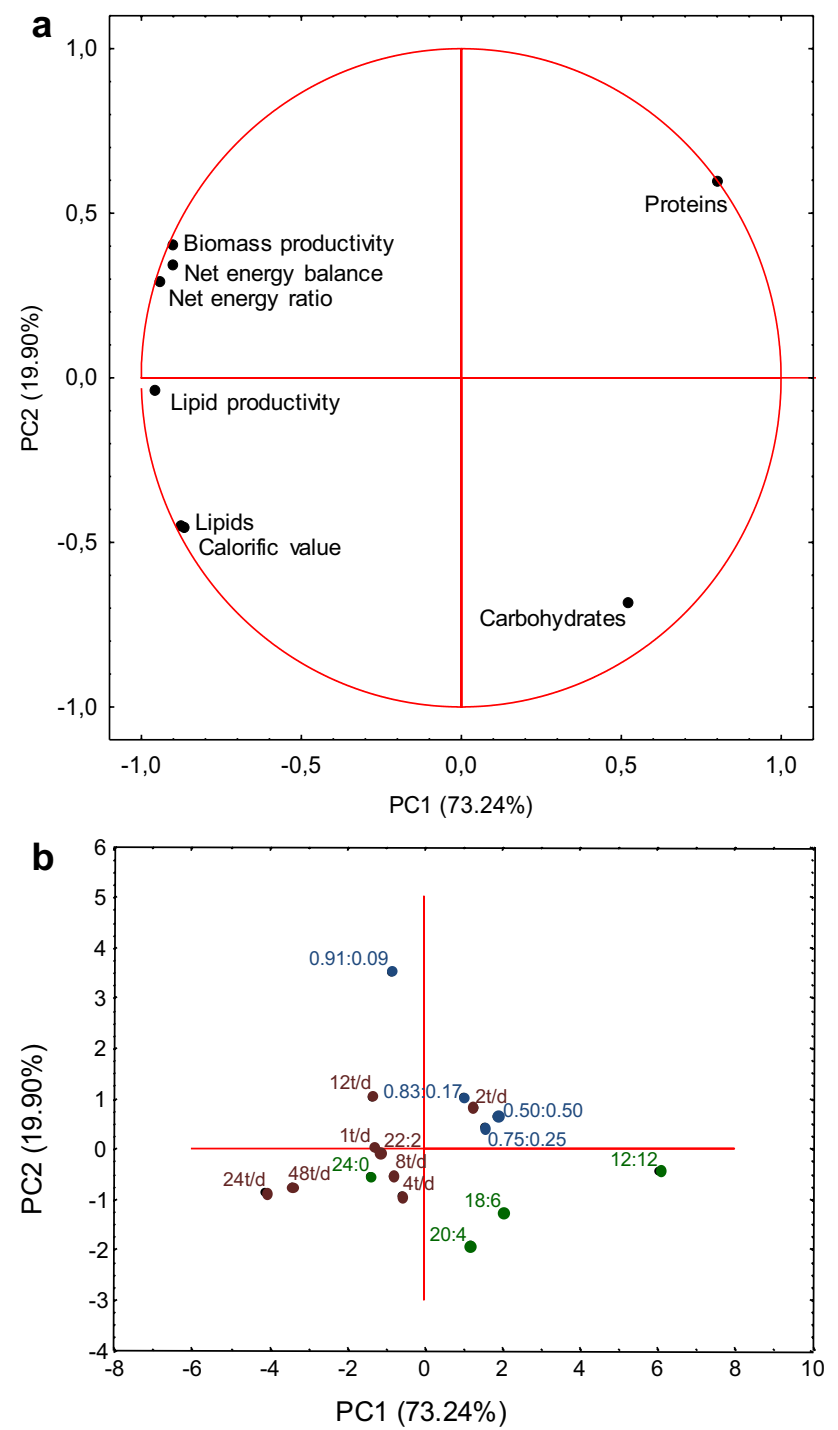

Fig. 3 PCA of chemical composition, calorific value, productivities and energy balance (a), under different light conditions (b)

Funding The authors are grateful to the Coordination for the Improvement of Higher Education Personnel (CAPES) (Grant Number 001) for the financial support.

\section{Compliance with ethical standards}

Conflict of interest The authors declare that there is no conflict of interest regarding the publication of the manuscript.
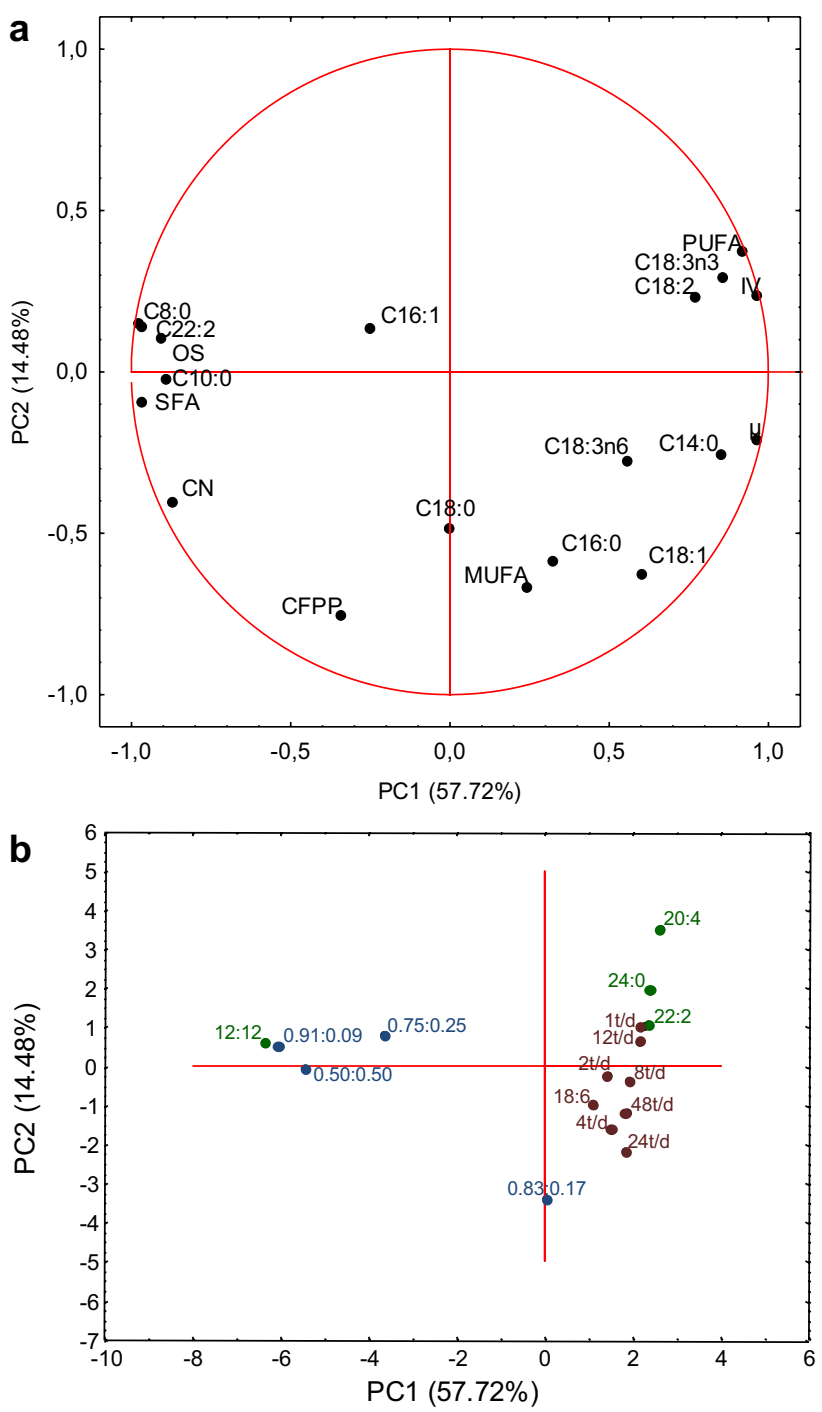

Fig. 4 PCA of fatty acid profile and fuel properties (a), under different light conditions (b)

\section{References}

1. Chen T, Liu J, Guo B, Ma X, Sun P, Liu B, Chen F (2015) Light attenuates lipid accumulation while enhancing cell proliferation and starch synthesis in the glucose-fed oleaginous microalga Chlorella zofingiensis. Nat Sci Rep 5:14936-14946

2. Su F, Li G, Fan Y, Yan Y (2016) Enhanced performance of lipase via microcapsulation and its application in biodiesel preparation. Nat Sci Rep 6:29670-29682

3. Chisti Y (2007) Biodiesel from microalgae. Biotechnol Adv 25:294-306

4. Chu FF, Chu PN, Shen XF, Lam PKS, Zeng RJ (2014) Effect of phosphorus on biodiesel production from Scenedesmus obliquus under nitrogen-deficiency stress. Bioresour Technol 152:241-246

5. Abomohra AEF, Jin W, El-Sheekh M (2016) Enhancement of lipid extraction for improved biodiesel recovery from the biodiesel promising microalga Scenedesmus obliquus. Energy Convers Manag 108:23-29 
6. Blanken W, Cuaresma M, Wijffels RH, Janssen M (2013) Cultivation of microalgae on artificial light comes at a cost. Algal Res 2:333-340

7. Abu-Ghosh S, Fixler D, Dubinsky Z, lluz D (2015) Flashing light in microalgae biotechnology. Bioresour Technol 203:357-363

8. Jacob-Lopes E, Scoparo CHG, Lacerda LMCF, Franco TT (2009) Effect of light cycles (night/day) on $\mathrm{CO}_{2}$ fixation and biomass production by microalgae in photobioreactors. Chem Eng Process 48:306-310

9. Takache H, Pruvost J, Marec H (2015) Investigation of light/ dark cycles effects on the photosynthetic growth of Chlamydomonas reinhardtii in conditions representative of photobioreactor cultivation. Algal Res 8:192-204

10. Zhou Q, Zhang P, Zhan G, Peng M (2015) Biomass and pigments production in photosynthetic bacteria wastewater treatment: effects of photoperiod. Bioresour Technol 190:196-200

11. George B, Pancha I, Desai C, Chokshi K, Paliwal C, Ghosh T, Mishra S (2015) Effects of different media composition, light intensity and photoperiod on morphology and physiology of freshwater microalgae Ankistrodesmus falcatus -A potential strain for bio-fuel production. Bioresour Technol 171:367-374

12. Krzeminska I, Pawlik-Skowronska B, Trzcinska M, Tys J (2014) Influence of photoperiods on the growth rate and biomass productivity of green microalgae. Bioprocess Biosyst Eng 37:735-741

13. Mitra M, Patidar SK, George B, Shah F, Mishra S (2015) A euryhaline Nannochloropsis gaditana with potential for nutraceutical (EPA) and biodiesel production. Algal Res 8(161):167

14. Rippka R, Derulles J, Watrerbury JB, Herdman M, Stainer RY (1979) Generic assignments, strain histories and properties of pure cultures of cyanobacteria. J Gen Microbiol 111:1-61

15. AOAC (2000) Official Methods of Analysis of AOAC International. AOAC International, Gaithersburg

16. Bligh EG, Dyer JW (1959) A rapid method of total lipid extraction and purification. Can J Biochem Physiol 37:911-917

17. Watt BK, Merrill AL (1963) Composition of foods. Agriculture Handbook No 8. Department of Agriculture, Washington

18. Hartman L, Lago RCA (1973) Rapid preparation of fatty acids methyl esters. Lab Pract 22:475-476

19. Talebi AF, Tabatabaei M, Chisti Y (2014) Biodiesel Analyzer: a user-friendly software for predicting the properties of prospective biodiesel. Biofuel Res J 2:55-57

20. ISO (International Organization for Standardization), 2006. ISO 14040:2006(E) Environmental management - life cycle assessment - principles and framework

21. Xue C, Goh QY, Tan W, Hossain I, Chen WN, Lau R (2011) Lumostatic strategy for microalgae cultivation utilizing image analysis and chlorophyll a content as design parameters. Bioresour Technol 102:6005-6012

22. Vendruscolo RG, Fagundes MB, Maroneze MM, de Nascimento TC, de Menezes CR, Barin JS, Zepka LQ, Jacob-Lopes E, Wagner R (2019) Scenedesmus obliquus metabolomics: effect of photoperiods and cell growth phases. Bioprocess Biosyst Eng 42(5):727-739

23. Seyfabadi J, Ramezanpour Z, Khoeyi JA (2011) Protein, fatty acid, and pigment content of Chlorella vulgaris under different light regimes. J Appl Phycol 23:721-726

24. Falkowsk PG, Raven JA (1997) Aquatic photosynthesis. Princeton University Press, New Jersey

25. Maroneze MM, Siqueira SF, Vendruscolo RG, Wagner $R$, de Menezes CR, Zepka LQ, Jacob-Lopes E (2016) The role of photoperiods on photobioreactors-a potential strategy to reduce costs. Bioresour Technol 219:493-499

26. Queiroz MI, Hornes MO, Silva-Manetti AG, Jacob-Lopes E (2011) Single-cell oil production by cyanobacterium Aphanothece microscopica Nägeli cultivated heterotrophically in fish processing wastewater. Appl Energy 88:3438-3443

27. Sharma KK, Schuhmann H, Schenk PM (2012) High lipid induction in microalgae for biodiesel production. Energies 5:1532-1553

28. Illman AM, Scragg AH, Shales SW (2000) Increase in Chlorella strains calorific values when grown in low nitrogen medium. Enzyme Microb Technol 27:631-635

29. Lim KC, Zaleha K (2013) Effect of photoperiod on the cellular fatty acid composition of three tropical marine microalgae. Malays Appl Biol 42:41-49

30. Mandotra SK, Kumar P, Suseela MR, Nayaka S, Ramteke PW (2016) Evaluation of fatty acid profile and biodiesel properties of microalga Scenedesmus abundans under the influence of phosphorus, pH and light intensities. Bioresour Technol 201:222-229

31. Mekuto L, Musingadi, D (2019) A dataset representing the impact of cyanide on the fatty acid profile of Scenedesmus obliquus. Data in brief 24(1):103900-103903

32. Qu Z, Duan P, Cao X, Liu M, Lin L, Li M (2019) Comparison of monoculture and mixed culture (Scenedesmus obliquus and wild algae) for $\mathrm{C}, \mathrm{N}$, and $\mathrm{P}$ removal and lipid production. Environ Sci Pol Res 26:20961-20968

33. Bagchi SK, Patnaik R, Sonkar S, Koley S, Rao PS, Mallick N (2019) Qualitative biodiesel production from a locally isolated chlorophycean microalga Scenedesmus obliquus (Turpin) Kützing GA 45 under closed raceway pond cultivation. Renew Energy 139:976-987

34. ASTM-American Society for Testing and Materials (2002) ASTM 6751 - standard specification for biodiesel fuel (B100) blend stock for distillate fuels. ASTM, West Conshohocken

35. EN-European Standard, (2003) UNE-EN 14214 - automotive fuel - fatty acid methyl esters (FAME) for diesel engine - requirements and test methods. European Standard, Pilsen

36. ANP-National Petroleum Agency (2003) ANP 255 - Provisional Brazilian Biodiesel Standard. ANP, Brasília

37. Ramos MJ, Fernández CM, Casas A, Rodríguez L, Pérez A (2009) Influence of fatty acid composition of raw materials on biodiesel properties. Bioresour Technol 100:261-268

38. Geacai S, Iulian O, Nita I (2015) Measurement, correlation and prediction of biodiesel blends viscosity. Fuel 143:268-274

39. Gülün $M$, Bilgin $A$ (2016) Two-term power models for estimating kinematic viscosities of different biodiesel-diesel fuel blends. Fuel Process Technol 149:121-130

40. Santos AM, Deprá MC, Santos AM, Zepka LQ, Jacob-Lopes E (2015) Aeration energy requirements in microalgal heterotrophic bioreactors applied to agroindustrial wastewater treatment. Cur Biotechnol 5:249-254

41. Lelieveld J, Klingmüller K, Pozzer A, Burnett RT, Haines A, Ramanathan V (2019) Effects of fossil fuel and total anthropogenic emission removal on public health and climate. Proc Nat Acad Sci 116(15):7192-7197

Publisher's Note Springer Nature remains neutral with regard to jurisdictional claims in published maps and institutional affiliations. 